\title{
Fault Diagnosis of Batch Reactor Using Machine Learning Methods
}

\author{
Sujatha Subramanian, ${ }^{1}$ Fathima Ghouse, ${ }^{2}$ and Pappa Natarajan ${ }^{3}$ \\ ${ }^{1}$ Department of Electronics and Instrumentation Engineering, Adhiyamaan College of Engineering, Hosur, Krishnagiri, \\ Tamil Nadu 635 109, India \\ ${ }^{2}$ Department of Information Technology, Adhiyamaan College of Engineering, Hosur, Krishnagiri, Tamil Nadu 635 109, India \\ ${ }^{3}$ Department of Instrumentation Engineering, Madras Institute of Technology, Anna University, Chennai, \\ Tamil Nadu 600 044, India \\ Correspondence should be addressed to Sujatha Subramanian; saransakthi@sify.com
}

Received 3 January 2014; Accepted 4 March 2014; Published 22 April 2014

Academic Editor: Azah Mohamed

Copyright (C) 2014 Sujatha Subramanian et al. This is an open access article distributed under the Creative Commons Attribution License, which permits unrestricted use, distribution, and reproduction in any medium, provided the original work is properly cited.

\begin{abstract}
Fault diagnosis of a batch reactor gives the early detection of fault and minimizes the risk of thermal runaway. It provides superior performance and helps to improve safety and consistency. It has become more vital in this technical era. In this paper, support vector machine (SVM) is used to estimate the heat release $\left(Q_{r}\right)$ of the batch reactor both normal and faulty conditions. The signature of the residual, which is obtained from the difference between nominal and estimated faulty $Q_{r}$ values, characterizes the different natures of faults occurring in the batch reactor. Appropriate statistical and geometric features are extracted from the residual signature and the total numbers of features are reduced using SVM attribute selection filter and principle component analysis (PCA) techniques. artificial neural network (ANN) classifiers like multilayer perceptron (MLP), radial basis function (RBF), and Bayes net are used to classify the different types of faults from the reduced features. It is observed from the result of the comparative study that the proposed method for fault diagnosis with limited number of features extracted from only one estimated parameter $\left(Q_{r}\right)$ shows that it is more efficient and fast for diagnosing the typical faults.
\end{abstract}

\section{Introduction}

Batch and semibatch reactors are extensively used in fine chemicals, biochemicals, pharmaceuticals, and food industries for the production of small amounts of products with high added value. As these processes have become more automated and more flexible, the demands on their efficiency have increased, creating more complexity in operation and control. However, the frequency of accidents increased involving important consequences on the human, natural, and economic environment $[1,2]$. Therefore, fault diagnosis has become a major research topic. Batch processes usually involve a lot of variables that interrelate with one another. When any of these variables diverge away from their specified limits, a fault occurs. There are a plenty of studies on fault diagnosis varying from analytical methods to artificial intelligence and statistical approaches. The approaches of fault detection are based on the threshold checking in the past. Venkatasubramanian and Chan [3] proposed fault diagnosis to the continuous stirred tank reactors with neural network and identified six kinds of faults. The application of neural networks in fault diagnosis of chemical process focuses on the following aspects such as using as a classifier, using as a dynamic forecast model, and combining with other diagnostic methods. Later, pattern classification and model identification [4], EKF based fault detection [5], and fault diagnosis of ball bearing using machine learning method [6] were used.

In this paper, SVM model is used to generate the residual images. Fault classification has been done from the extracted image features. SVM is a novel machine learning method based on statistical learning theory. The SVM utilizes a hyperplane with maximum margin to produce a good generalization performance by separating different classes. As 
a result, SVM has been widely used for many applications, such as time series forecasting, fault detection, modelling of nonlinear dynamic systems, one-class SVM for machine fault detection and classification [7], SVM for copper clad laminate defects classification [8], and SVM for fault diagnosis of a steam turbine [9].

For this study, different major fault types like actuator fault, sensor fault, and process fault are considered. Hence the fault residuals are generated from the output of the nominal model and this faulty model. Data based fault diagnosis method requires a large amount of historical data. To make this method be more efficient, the first step is feature extraction [10]. From the residuals signature, the most appropriate statistical and geometrical features are extracted and among these 15 features are selected. Through this characteristic extraction, the data can be transformed to the prior information of fault diagnosis system. SVM attribute filter is employed to rank the features, in order to reduce the input data dimension which makes the better performance of the classifier. And its performance is compared based on PCA feature reduction also.

This paper is mainly focused on identifying fault classification of batch reactor from the residual features using artificial intelligent classifiers such as multilayer perceptron (MLP), radial basis function (RBF), and Bayes net. The paper is organized as follows: Section 2 describes machine learning methods used in this work; Section 3 explains the case study of the well-known batch reactor; Section 4 gives fault identification method; Section 5 shows and discusses the simulation results. Finally, the conclusion from this work is presented in Section 6.

\section{Machine Learning Methods}

In this paper, the machine learning methods like SVM, ANN like MLP, and RBF are used. SVM is a supervised learning method, which is motivated in maximizing the ability to generalize well from a small number of training samples by mapping the original space into a high dimensional inner product space called feature space via a kernel. The SVM formulation follows structural risk minimization (SRM) principle in which an upper bound on the generalization error is minimized, whereas the error risk minimization (ERM) minimizes the prediction error on the training data. This equips the SVM with a greater potential to generalize the input-output relationship learnt during its training phase for making good predictions for new input data [11].

SVM's solutions are characterized by convex optimization problems. So it can be applied in settling pattern recognition problems with small samples, nonlinearity, and higher dimensions. SVM can easily be introduced into learning problems such as function estimation.

In the batch reactor, the heat released by the reaction affects the dynamics of the reactor temperature. This term depends on the initial concentration, which is usually measurable at a very low sampling rate, not suitable for real time control or estimation. So any fault occurring in the batch reactor will have the impact on the heat release of the reactor.

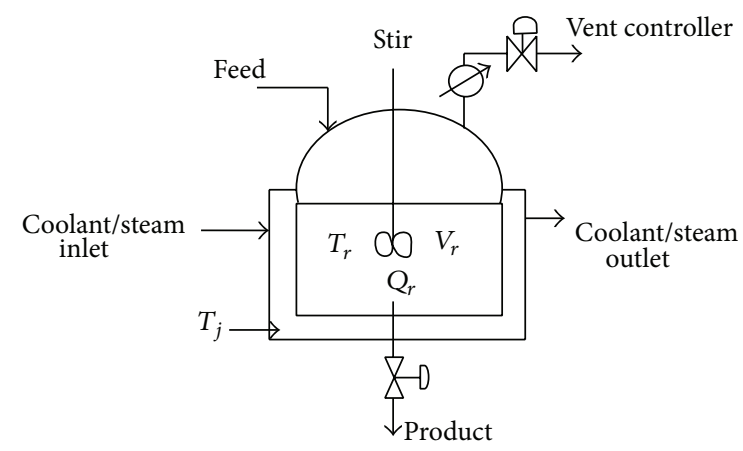

FIGURE 1: Schematic diagram of a jacketed batch reactor.

So a model developed based on the heat release of the reactor $\left(Q_{r}\right)$ which can predict the type of fault occurred. But the quantity of $Q_{r}$ is not directly measurable one. So an estimator is required to estimate it. Here SVM is used to build the estimator model.

Similarly, for classification of different faults, the usual ANN classifiers are used in this work. There are various neural network architectures but the application considered in this work has used MLP with back propagation learning algorithm, RBF, and the Bayes net [12-16].

\section{Case Study}

The proposed fault diagnosis scheme is applied to the batch reactor by Cott and Macchietto [17], Aziz et al. [18], Mujtaba et al. [19], and Sujatha and Pappa [20]. The complex reaction scheme of a batch reactor is a representative of many industrial reactions as shown in Figure 1. The batch reactor is inherently a dynamic process. The reactions I and II of the batch reactor are given in the following equation:

$$
\begin{aligned}
& A+B \longrightarrow C, \\
& A+C \longrightarrow D,
\end{aligned}
$$

where $A, B$ are the raw materials, $C$ is the desired product, and $D$ is the waste product.

This benchmark model is given on the basis of reaction equation (1), competent of simulating the reactions like the reactor temperature, jacket temperature, and heat release of reactor under nominal operating conditions and also under various faulty conditions.

These simulations are run under closed loop control with generic model controller (GMC) [20, 21]. The total running time of the batch process is 120 minutes ( 2 hours). The batch reactor model equations are given below:

$$
\frac{d M_{A}}{d t}=-R_{1}-R_{2}
$$




$$
\begin{aligned}
& \frac{d M_{B}}{d t}=-R_{1}, \\
& \frac{d M_{C}}{d t}=R_{1}-R_{2}, \\
& \frac{d M_{D}}{d t}=R_{2}, \\
& R_{1}=k_{1} M_{A} M_{B} \text {, } \\
& R_{2}=k_{2} M_{A} M_{C} \text {, } \\
& k_{1}=\exp \left(\frac{k_{1}^{1}-k_{1}^{2}}{\left(T_{r}+273.15\right)}\right) \text {, } \\
& k_{2}=\exp \left(\frac{k_{2}^{1}-k_{2}^{2}}{\left(T_{r}+273.15\right)}\right) \text {, } \\
& \frac{d T_{r}}{d t}=\frac{\left(Q_{r}+Q_{j}\right)}{M_{r} C_{p r}} \\
& \frac{d T_{j}}{d t}=\frac{\left(T_{j}^{s p}-T_{j}\right)}{\tau_{j}}-\frac{Q_{j}}{V_{j} \rho_{j} C_{p j}}, \\
& Q_{r}=-\Delta H_{1} R_{1}-\Delta H_{2} R_{2}, \\
& M_{r}=M_{A}+M_{B}+M_{C}+M_{D}, \\
& C_{p r}=\frac{C_{p A} M_{A}+C_{p B} M_{B}+C_{p C} M_{C}+C_{p D} M_{D}}{M_{r}}, \\
& Q_{j}=U A\left(T_{j}-T_{r}\right) .
\end{aligned}
$$

The initial values of the above mentioned process parameters of $\left[M_{A}, M_{B}, M_{C}, M_{D}, T_{j}, T_{r}\right]$ are $[12.0,12.0,0.0,0.0$, $20.0,20.0]$ at $t=0$. The reactor temperature is used as the control variable and is bounded between $20^{\circ}$ and $100^{\circ} \mathrm{C}$ and the jacket temperature is the manipulated variable and it is bounded between $20^{\circ}$ and $120^{\circ} \mathrm{C}$. All the nominal parameters and constant values used in the model equations (2) are given in Table 1.

\begin{tabular}{|c|c|c|}
\hline & Constant parameters & Values \\
\hline$C_{p A}$ & $\begin{array}{l}\text { Specific heat capacity of component } \\
A\end{array}$ & $18.0 \mathrm{kcal} / \mathrm{kmol}^{\circ} \mathrm{C}$ \\
\hline$C_{p B}$ & $\begin{array}{l}\text { Specific heat capacity of component } \\
B\end{array}$ & $40.0 \mathrm{kcal} / \mathrm{kmol}^{\circ} \mathrm{C}$ \\
\hline$C_{p C}$ & $\begin{array}{l}\text { Specific heat capacity of component } \\
\text { C }\end{array}$ & $52.0 \mathrm{kcal} / \mathrm{kmol}^{\circ} \mathrm{C}$ \\
\hline$C_{p D}$ & $\begin{array}{l}\text { Specific heat capacity of component } \\
D\end{array}$ & $80.0 \mathrm{kcal} / \mathrm{kmol}^{\circ} \mathrm{C}$ \\
\hline$\Delta H_{1}$ & Heat of reaction of reaction 1 & $-10000.0 \mathrm{kcal} / \mathrm{kmol}$ \\
\hline$\Delta H_{2}$ & Heat of reaction of reaction 2 & $-6000.0 \mathrm{kcal} / \mathrm{kmol}$ \\
\hline$C_{p}$ & Mass heat capacity of reactant & $0.45 \mathrm{kcal} / \mathrm{kg}^{\circ} \mathrm{C}$ \\
\hline$C_{p j}$ & Molar heat capacity of component $j$ & $0.45 \mathrm{kcal} / \mathrm{kg}^{\circ} \mathrm{C}$ \\
\hline$U$ & Heat transfer coefficient & $9.76 \mathrm{kcal} / \mathrm{min} \mathrm{m}^{2}{ }^{\circ} \mathrm{C}$ \\
\hline$\rho_{j}$ & Density & $1000.0 \mathrm{~kg} / \mathrm{m}^{3}$ \\
\hline$k_{1}^{1}$ & $\begin{array}{l}\text { Preexponential rate constant for } \\
\text { reaction } 1\end{array}$ & 20.9057 \\
\hline$k_{1}^{2}$ & $\begin{array}{l}\text { Preexponential rate constant for } \\
\text { reaction } 1\end{array}$ & 10000 \\
\hline$k_{2}^{1}$ & $\begin{array}{l}\text { Preexponential rate constant for } \\
\text { reaction } 2\end{array}$ & 38.9057 \\
\hline$k_{2}^{2}$ & $\begin{array}{l}\text { Preexponential rate constant for } \\
\text { reaction } 2\end{array}$ & 17000 \\
\hline$V_{j}$ & Jacket volume & $0.6921 \mathrm{~m}^{3}$ \\
\hline$A$ & Heat transfer area & $6.24 \mathrm{~m}^{2}$ \\
\hline$M_{r}$ & Number of moles of component & $1560 \mathrm{~kg}$ \\
\hline$\tau_{j}$ & Jacket time constant & $3.0 \mathrm{~min}$ \\
\hline
\end{tabular}

\section{Fault Diagnosis of the Batch Reactor}

Fault can be defined as any nonpermitted deviation of process behaviour from an acceptable one. So fault diagnosis is the problem of identifying and isolating unanticipated changes in a process. Diagnosis is a challenging problem due to several factors such as monitoring the number of variables, occurrences of the process complexity, and the variety of process failures. The failures can be broadly categorized into three types such as actuator faults, sensor faults, and process faults. The fault types are inspired from the relevant literature [22] presented in Figure 2.
TABLE 1: Nominal values of the parameters.

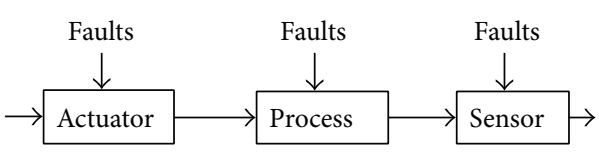

FIGURE 2: Types of faults.

Faults can be defined as follows.

(i) Process faults: processes that occur below a certain level of detail are generally represented as lumped parameters in process models. An example of such a lumped parameter in this batch reactor is the fouling factor. Changes in these parameters are termed as process or parametric faults.

(ii) Sensor failure: while all sensors have random errors, sensor failures refer to gross errors such as bias, measurement with noise, and frozen sensors.

Controller and actuator fault: the actuator faults are mostly caused by the nonlinear characteristics of the control valve by hysteresis, stiction, friction, and poor controller tuning. Actuator action in the presence of fault can be represented as $u_{a}(t)=u(t)+f_{a}(t)$ where $f_{a}(t)$ is the actuator fault vector. Abrupt constant bias has been given via the vector $f_{a}(t)=\delta u$, so that the actuator action becomes 


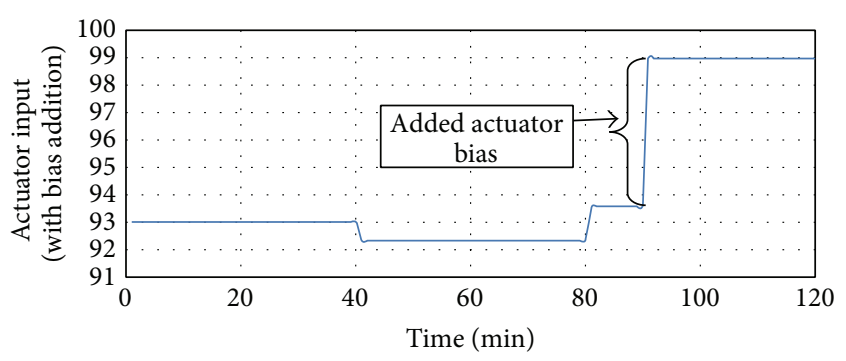

FIGURE 3: Simulated actuator fault by introducing bias at the time of 80 minutes.

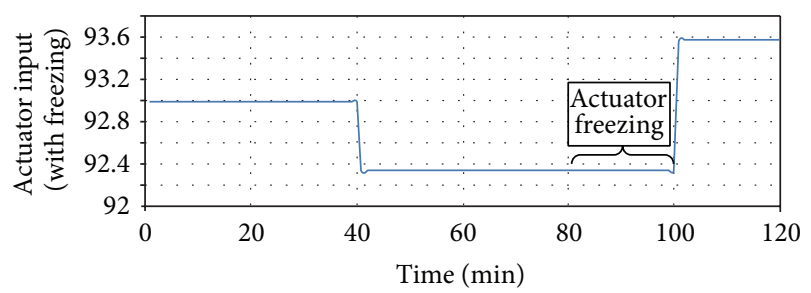

FIGURE 4: Simulated actuator fault by introducing freezing at the time interval (80-100 minutes).

\begin{tabular}{|c|c|c|}
\hline$T_{r}(k-2)$ & $T_{r}(k-1)$ & $T_{r}(k)$ \\
\hline & $T_{j}(k-1)$ & $T_{j}(k)$ \\
\cline { 2 - 3 } & $Q_{r}(k-1)$ & $Q_{r}(k)$ \\
\hline
\end{tabular}

$\begin{array}{ll}\square & \text { Input } \\ \square & \text { Output }\end{array}$

FIGURE 5: Input/output mapping of the SVM heat release estimator.

$u_{a}(t)=u(t)+\delta u$ as shown in Figure 3. Similarly the freezing of the actuator at certain time has been shown as $f_{a}(t)=$ $-u(t)$, so that the actuator action is $u_{a}(t)=0$ as shown in Figure 4 . The faults that occurred in the batch reactor have a relationship with the heat release of the reactor.

4.1. SVM Estimator Model Based Fault Detection. Model based fault detection method is developed based on the assumption that the developed model is replica of the real plant dynamics. The input-output data are obtained by simulating the batch reactor with nominal operating conditions. The different faults have been introduced in the reactor through simulation by using MATLAB software. From the simulated input and output data, SVM estimator model is developed using LIBSVM toolbox. The heat release of the reactor $\left(Q_{r}\right)$ which is not a measurable parameter is estimated through the SVM model.

4.2. Training and Testing of the Estimator. Training the SVM estimator as shown in Figure 6 is an iterative process in which

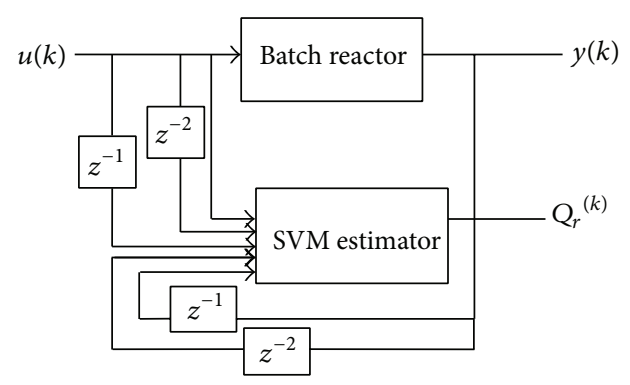

FIgURE 6: Training method for the heat release estimator.

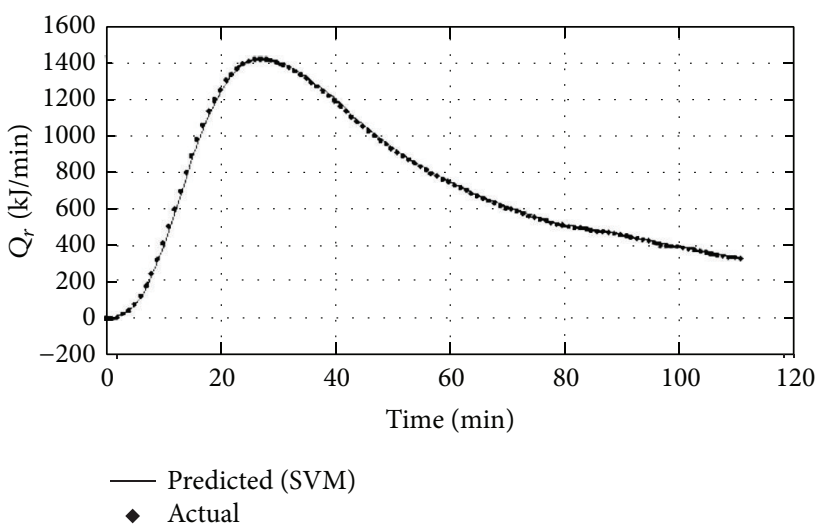

FIGURE 7: Response of SVM $Q_{r}$ estimator under normal condition.

the SVM is given inputs along with the desired outputs. In this work, the SVM estimates the heat release of the reactor $\left(Q_{r}\right)$. The input and output mapping of the estimator is shown in Figure 5 where the past and present values of the reactor temperature and jacket temperature and the past values of the $Q_{r}$ are considered as the input data. The estimator model is developed by selecting the SVM parameters such as $\gamma=90$, $\sigma=100$ and the Radial Basis Function (RBF) as kernel to build and train the estimator as shown in Figure 6. Without any fault, the response of the estimator is shown in Figure 7.

The estimator models are developed under both normal and faulty conditions. The difference between faulty and nominal model is called residual (in terms of $Q_{r}$ ) which is the important part of the fault diagnosing method as shown in Figure 8. Based on the residual patterns, the faults are identified through ANN classifiers.

4.3. Different Faults. Three different types of faults such as process fault, sensor fault, and actuator fault are introduced and data is collected for estimation of heat release of the reactor $\left(Q_{r}\right)$. Each fault is introduced through simulation and the respective plant input and output data are collected every time. Table 2 shows the assigned fault for this work.

\subsubsection{Process Fault}

(i) Change in heat transfer coefficient $(U)$ : because of the fouling effect present in the heat exchanger, $U$ changes from its nominal value from batch to batch. Variation 


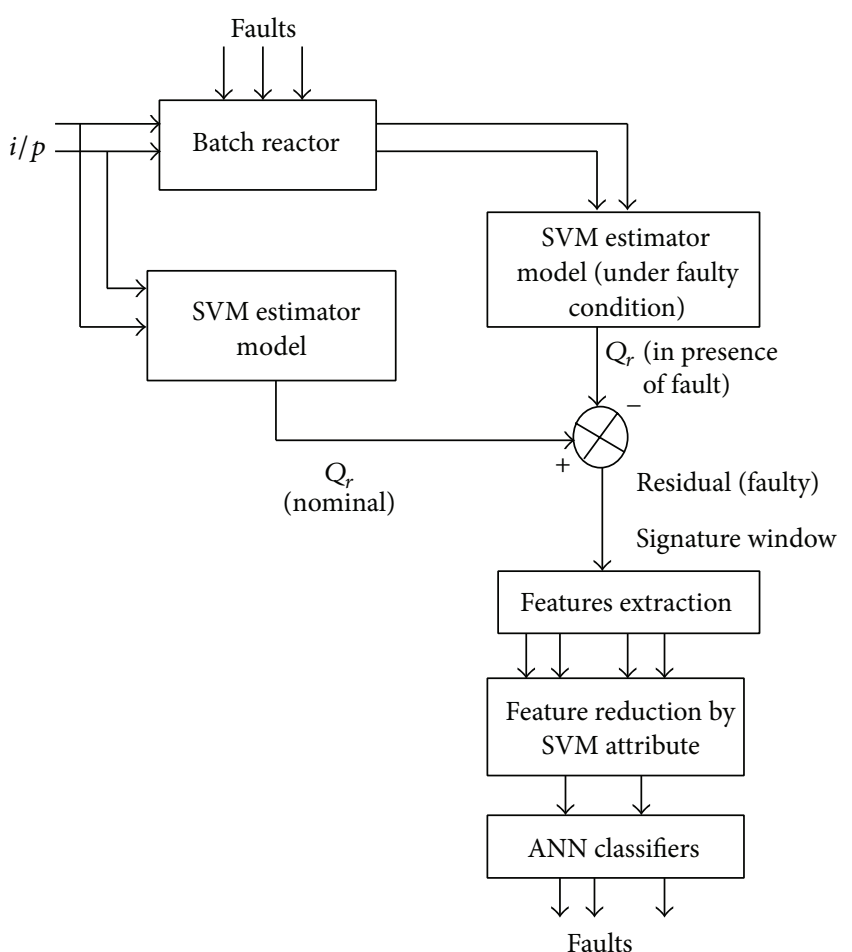

FIGURE 8: Block diagram of fault diagnosis process.

TABLE 2: Fault description.

\begin{tabular}{lccc}
\hline $\begin{array}{l}\text { Sl. } \\
\text { number }\end{array}$ & $\begin{array}{c}\text { Fault } \\
\text { types }\end{array}$ & Fault description & Category \\
\hline 1 & Fault1 & $\begin{array}{c}\Delta H-\text { heat of reaction } \\
\text { change } \\
M_{a}, M_{b} \text { change (initial } \\
2\end{array}$ & Process fault \\
3 & Fault2 & $\begin{array}{c}\text { values of input component } \\
\text { feed change) }\end{array}$ & Process fault \\
4 & Fault3 & $\begin{array}{r}\text { Heat transfer coefficient } \\
\text { change }(U)\end{array}$ & Process fault \\
5 & Fault5 & $\begin{array}{c}\text { Actuator freezing } \\
\text { Actuator biasing }\end{array}$ & Actuator fault \\
6 & Fault6 & $\begin{array}{c}\text { Sensor abrupt zero, biasing } \\
\text { and addition of white noise }\end{array}$ & Actuator fault \\
\hline
\end{tabular}

in $\mathrm{Q}_{r}$ residual for $10 \%, 20 \%, 30 \%$, and $40 \%$ increase and decrease in $U$ are shown in Figure 9.

(ii) Change in heat of reaction $(\Delta H)$ : the actual value of heat of reaction may not be available in the open literature and subsequently it can be the basic for model mismatch due to change in unmeasured parameter. The variation in $Q_{r}$ residual for the heat of the reaction is reduced and increased by $10 \%$ and $25 \%$ from the nominal value as shown in Figure 10.

(iii) Change in initial charge of reactants $\left(M_{A}, M_{B}\right)$ : a change in product demand and accidental failure of the charging system or scale-up issues at the design stage will be the causes for the change in the operating conditions. The variation in $Q_{r}$ residual for $10 \%, 20 \%$,
$25 \%$, and $30 \%$ decrease and increase in initial charge are as shown in Figure 11.

In the heat release of the reactor residual patterns for the process fault, the differences in sign of magnitude, sluggishness of the response, decrease of the magnitude, and change of the starting position of the curve are observed.

4.3.2. Actuator Fault. The actuator fault considered here is as follows.

(i) The addition of bias in the actuator shows the sticking nature of the actuator as shown in Figure 3.

(ii) The actuator freezing occurred in the time interval 80 to 100 minutes as shown in Figure 4.

The residuals from the actuator faults as freezing at the different time intervals and biasing are shown in Figures 12 and 13 .

From the actuator fault of both freezing and biasing signatures, abrupt change is identified at the moment of fault occurring and based on the duration; the magnitude and the pattern of the residual vary.

4.3.3. Sensor Faults. The following sensor faults are considered in this work:

(i) jacket temperature and reactor temperature measurements with the white noise;

(ii) abrupt bias at sensor;

(iii) abrupt zero at sensor.

Variation in $Q_{r}$ residual for the sensor faults is shown in Figure 14.

The signature of the sensor fault pattern is varying with respect to the sources of different components and at the time of fault.

From the fault signatures, the relevant statistical and geometrical features are extracted. Here, 15 features such as area, mean, standard deviation, skew, kurtosis, fractional area, Feret's diameter, integrated density, and raw integrated density are extracted by using Image J software. Few of the features are explained below.

(i) Mean: average value of a signal is termed as mean value as given in

$$
\mu_{C}=\frac{1}{M N} \sum_{i} \sum_{j} P_{i j}^{c} .
$$

(ii) Standard deviation: it is a measure of energy content in the fault signature shown in

$$
\mathrm{SD}=\sqrt{\frac{n \sum x^{2}-\left(\sum x\right)^{2}}{n(n-1)}} .
$$

(iii) Skewness: it is a measure of symmetry or more precisely the lack of symmetry as expressed in

$$
\text { skewness }=\frac{n}{(n-1)(n-2)} \sum\left(\frac{x_{i}-\bar{x}}{s}\right)^{3} .
$$




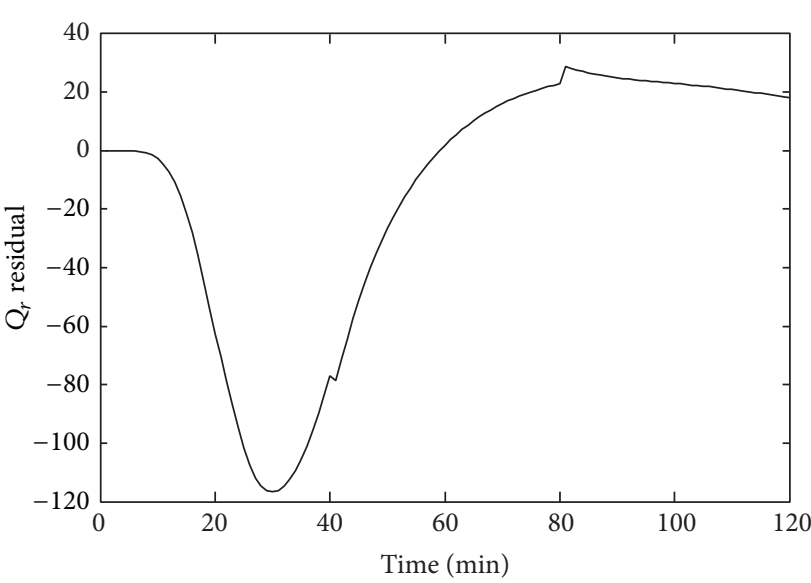

(a)

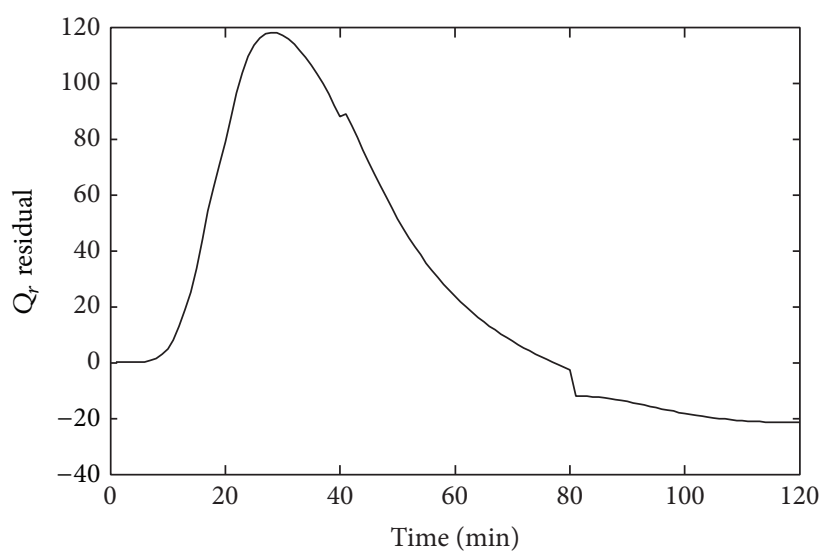

(c)

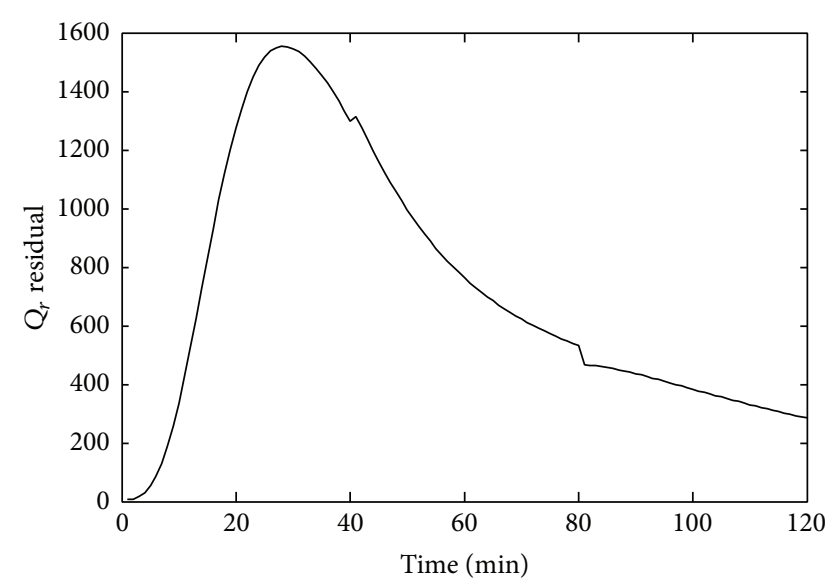

(b)

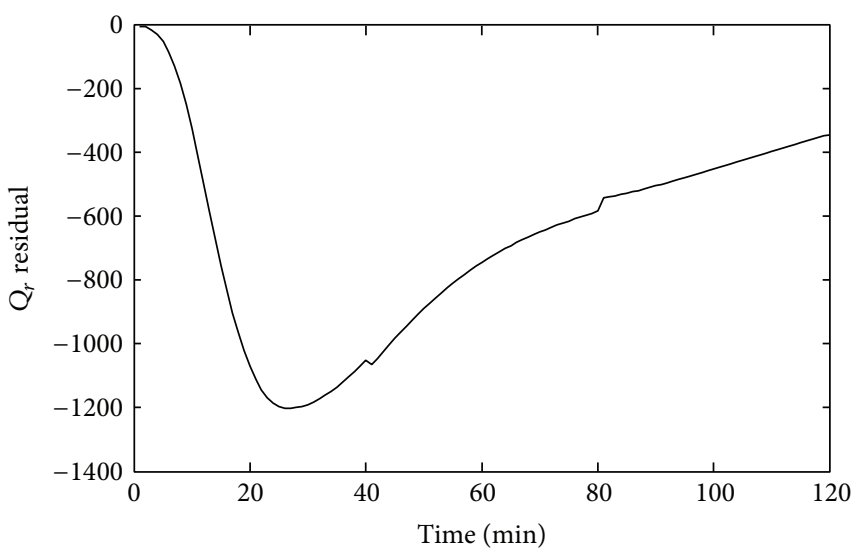

(d)

Figure 9: Residual (in terms of $Q_{r}$ ) due to change in heat transfer. (a) Residual (in terms of $Q_{r}$ ) due to $10 \%$ sudden increase in the heat transfer coefficient $(U)$. (b) Residual (in terms of $Q_{r}$ ) due to $20 \%$ reduction in the heat transfer coefficient $(U)$ ). (c) Residual (in terms of $Q_{r}$ ) due to $40 \%$ increase in the heat transfer coefficient $(U)$. (d) Residual (in terms of $Q_{r}$ ) due to $30 \%$ increase in the heat transfer coefficient $(U$ ).

(iv) Kurtosis: it is a measure of whether the data are peaked or flat relative to the normal distribution as given in

$$
\begin{aligned}
\text { kurtosis }= & {\left[\frac{n(n+1)}{(n-1)(n-2)(n-3)} \sum\left(\frac{x_{i}-\bar{x}}{s}\right)^{4}\right] } \\
& -3 \frac{(n-1)^{2}}{(n-2)(n-3)},
\end{aligned}
$$

where $n$ is the sample size and $s$ is the standard deviation.

\section{Results and Discussion}

The extracted features from the 24 simulated fault instances are listed in Table 3 . The instance means the number of data points in the input data. The listed features are reduced to decrease the computational complexity. The feature reduction as well as fault classification is carried out by using WEKA software.
5.1. SVM Attribute Filter Based Feature Selection. SVM attribute filter is used to reduce the number of features by ranking method. Intuitively, the SVM model is a representation of the points in space mapped, so that the features of separate categories are divided by a clear gap. The new features are then mapped into the same space and predicted to belong to a category based on which side of the gap they fall on. The features are given as the input to the SVM attribute filter. The attributes are ranked by the square of the weight assigned by the SVM. An attribute selection for multiclass problem is handled by ranking attributes for each class separately using a one-versus-all method. Based on the attribute ranking Table 4, the number of input features is selected for the classifier to improve the performance of it.

5.2. Classifier Performance. After selecting the fault as an attribute for class, the classification is carried out with the ANN classifiers. The output of the WEKA software gives 


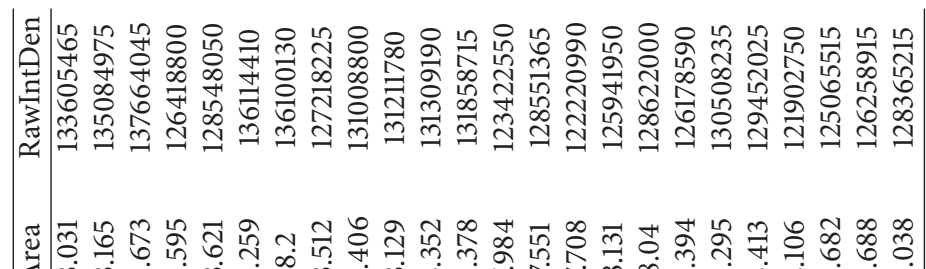
यद

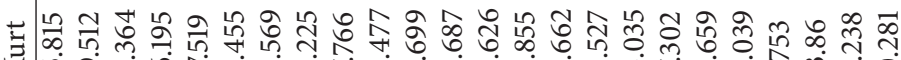

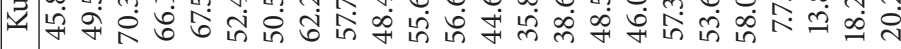

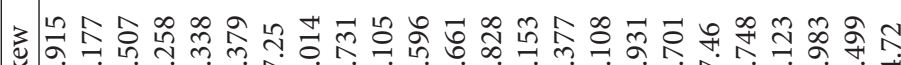

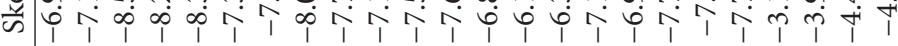

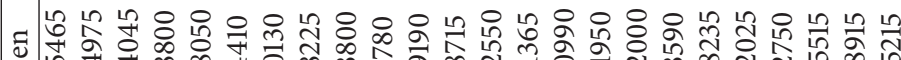

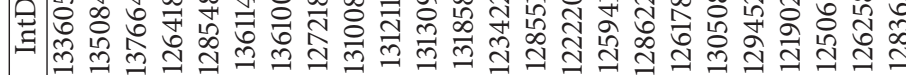

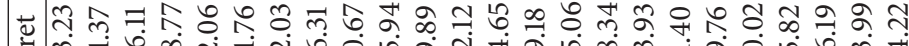

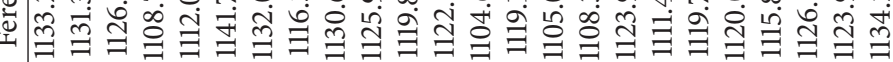

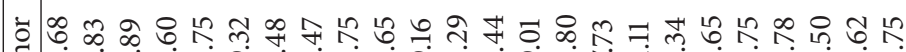

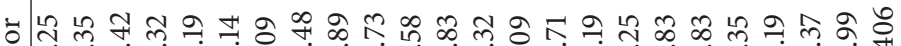

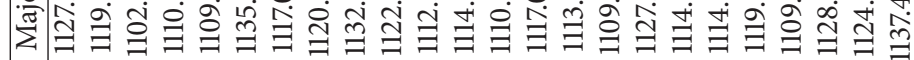

Y స्र 西

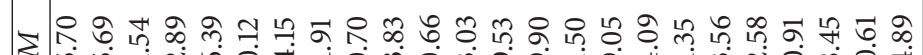
ॠ 垈

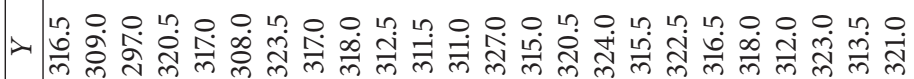

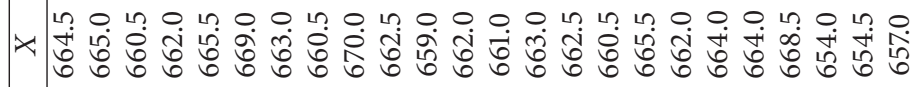

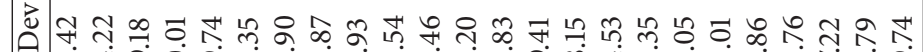

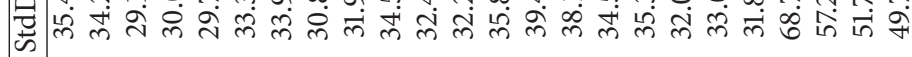

‡

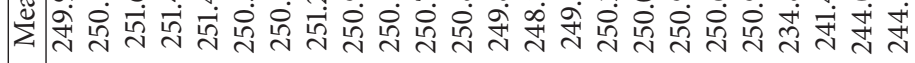

닌

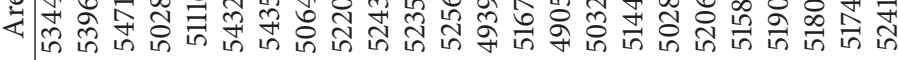

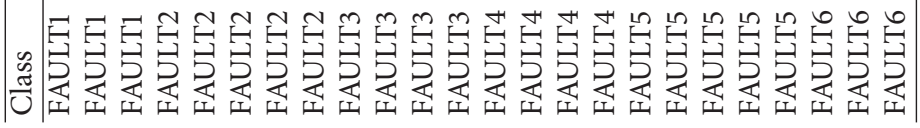




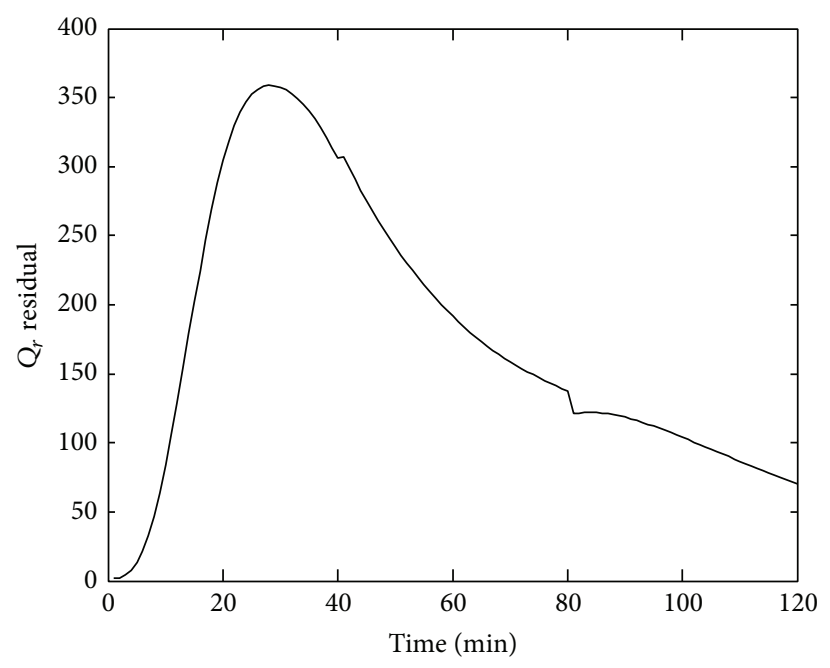

(a)

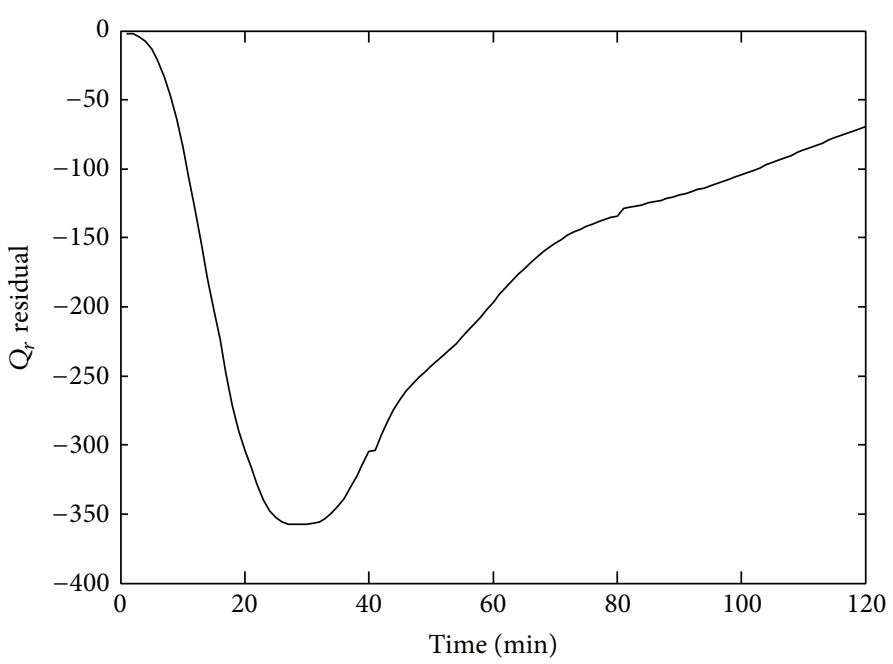

(b)

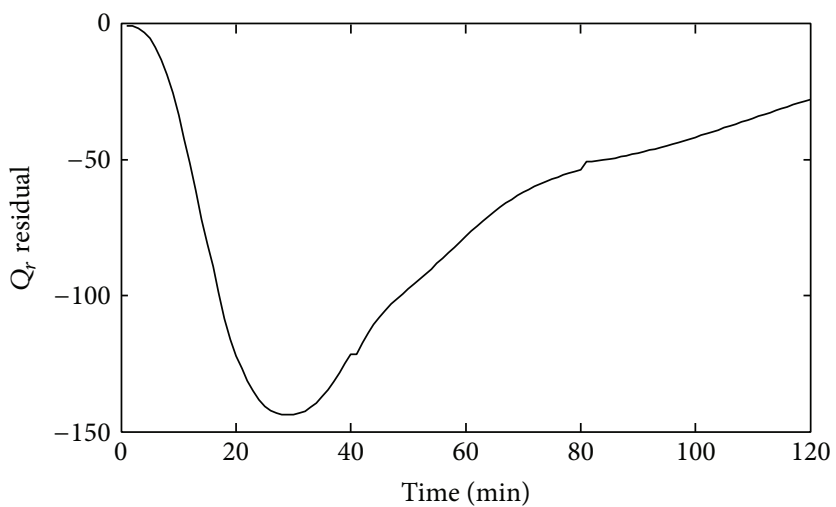

(c)

Figure 10: Residual (in terms of $Q_{r}$ ) due to change in heat of reaction. (a) Residual (in terms of $Q_{r}$ ) due to $25 \%$ decrease in heat of reaction. (b) Residual (in terms of $Q_{r}$ ) due to $25 \%$ increase in heat of reaction.(c) Residual (in terms of $Q_{r}$ ) due to $10 \%$ increase in heat of reaction.

TABLE 4: SVM ranking table.

\begin{tabular}{lcc}
\hline Sl. number & Name of the attributes & SVM ranking \\
\hline 1 & Minor & 15 \\
2 & Kurt & 14 \\
3 & Mean & 13 \\
4 & Feret & 12 \\
5 & $X$ & 11 \\
6 & $Y M$ & 10 \\
7 & $X M$ & 9 \\
8 & fArea & 8 \\
9 & Skew & 7 \\
10 & $Y$ & 6 \\
11 & Major & 5 \\
12 & StdDev & 4 \\
13 & Area & 3 \\
14 & RawIntDen & 2 \\
15 & IntDen & 1 \\
\hline
\end{tabular}

TABLE 5: Confusion matrix for different classifier.

\begin{tabular}{lccc}
\hline Bayes & ANN & RBF & Class \\
\hline a bcdef & abcdef & abcdef & \\
300000 & 300000 & 300000 & $\mathrm{a}=$ FAULT1 \\
200030 & 050000 & 050000 & $\mathrm{~b}=$ FAULT2 \\
004000 & 004000 & 004000 & $\mathrm{c}=$ FAULT3 \\
000310 & 000400 & 000400 & $\mathrm{~d}=$ FAULT4 \\
000050 & 000050 & 000050 & $\mathrm{e}=$ FAULT5 \\
000002 & 000002 & 000002 & $\mathrm{f}=$ FAULT6 \\
\hline
\end{tabular}

the confusion matrix, which shows a detailed accuracy of the classifier based on the class and evaluation of the success of the numeric prediction. In the multiple classification, the outcome of this test data displays a two-dimensional confusion matrix with a row and column for each class. Each matrix element shows the number of test examples for which the actual class is the row and the predicted class is the column. The confusion matrix shows each classifier's ability to achieve in the classification of faults as shown in Table 5. 


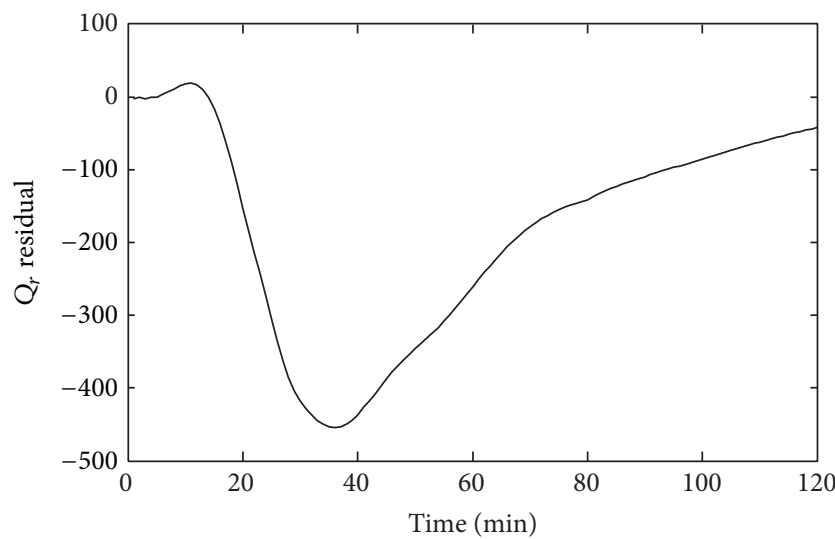

(a)

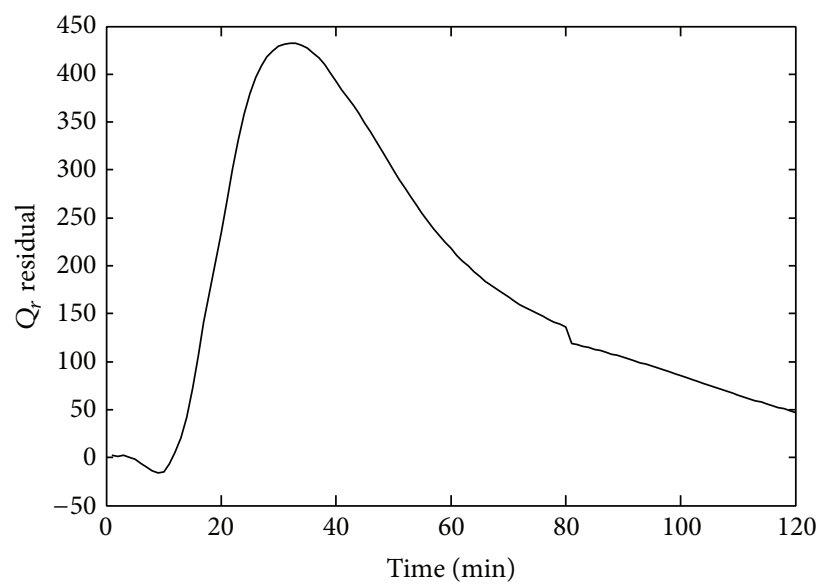

(c)

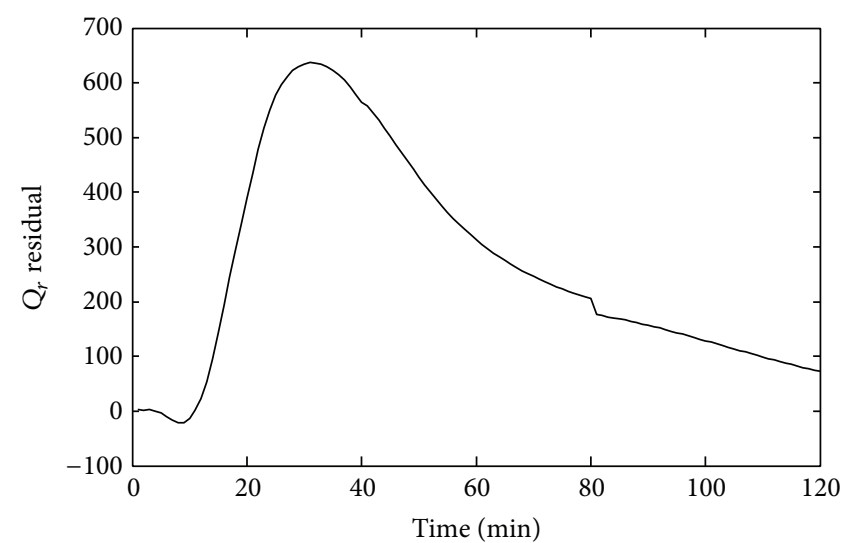

(b)

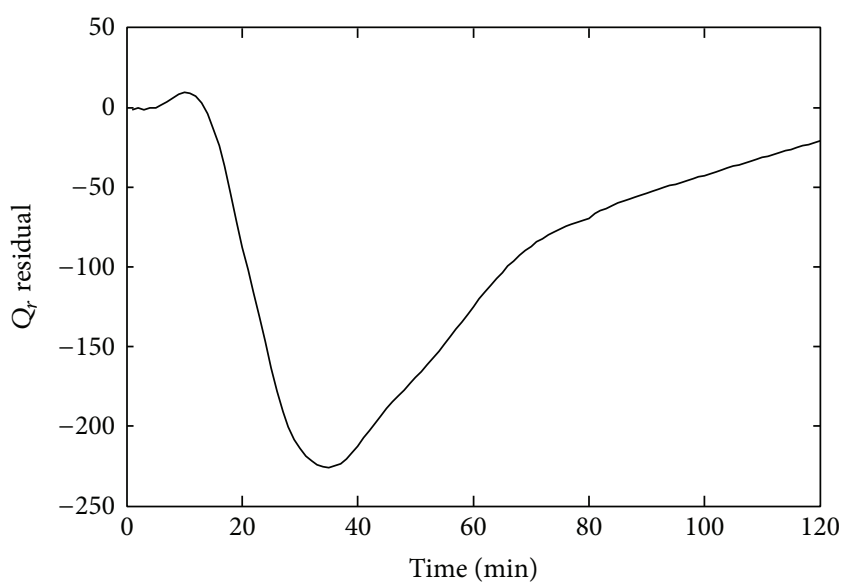

(d)

FIGURE 11: Residual (in terms of $Q_{r}$ ) due to change in initial values of the raw material $\left(M_{A}, M_{B}\right)$. (a) Residual (in terms of $Q_{r}$ ) due to $25 \%$ increase in the initial values of the raw material $\left(M_{A}, M_{B}\right)$. (b) Residual (in terms of $\left.Q_{r}\right)$ due to $30 \%$ decrease in the initial values of the raw material $\left(M_{A}, M_{B}\right)$. (c) Residual (in terms of $\left.Q_{r}\right)$ due to $20 \%$ decrease in the initial values of the raw material $\left(M_{A}, M_{B}\right)$. (d) Residual (in terms of $\left.Q_{r}\right)$ due to $10 \%$ decrease in the initial values of the raw material $\left(M_{A}, M_{B}\right)$.

TABLE 6: Results for training of fault features.

\begin{tabular}{|c|c|c|c|c|c|c|c|c|c|}
\hline \multirow{2}{*}{ Classifiers } & \multicolumn{3}{|c|}{ Bayes } & \multicolumn{3}{|c|}{ MLP } & \multicolumn{3}{|c|}{$\mathrm{RBF}$} \\
\hline & 5 features & 9 features & 15 features & 5 features & 9 features & 15 features & 5 features & 9 features & 15 features \\
\hline TP rate & 0.542 & 0.542 & 0.583 & 0.917 & 1 & 1 & 1 & 1 & 1 \\
\hline FP rate & 0.111 & 0.111 & 0.092 & 0.017 & 0 & 0 & 0 & 0 & 0 \\
\hline Precision & 0.399 & 0.399 & 0.384 & 0.927 & 1 & 1 & 1 & 1 & 1 \\
\hline Recall & 0.542 & 0.542 & 0.583 & 0.917 & 1 & 1 & 1 & 1 & 1 \\
\hline$F$-measure & 0.426 & 0.426 & 0.45 & 0.917 & 1 & 1 & 1 & 1 & 1 \\
\hline ROC area & 0.815 & 0.815 & 0.865 & 0.989 & 1 & 1 & 1 & 1 & 1 \\
\hline
\end{tabular}

From this, the radial basis function and multilayer perceptron have given better results as compared with the Bayes net classifier.

The training parameters for various classifiers for varying the number of features as 15 features, 9 features, and 5 features set as the input for the different classifiers are listed in Table 6 , which denotes the values of the true positive (TP rate), false positive (FP rate), precision, recall, F-measure, and ROC area.
The values of the TP rate, precision, recall, F-measure, and ROC area are " 1 " for RBF and MLP as compared with the Bayes net.

Classifiers performance criteria are shown in Table 7 for three sets of training pattern. From this table, MLP and RBF classified all instances correctly (100\%) compared with Bayes net. Comparing MLP and RBF, the mean absolute error, root mean square error, relative absolute error, and root relative 
TABle 7: Performance criteria of the classifiers.

\begin{tabular}{|c|c|c|c|c|c|c|c|c|c|}
\hline \multirow{2}{*}{ Classifiers } & \multicolumn{3}{|c|}{ Bayes } & \multicolumn{3}{|c|}{ MLP } & \multicolumn{3}{|c|}{$\mathrm{RBF}$} \\
\hline & 5 features & 9 features & 15 features & 5 features & 9 features & 15 features & 5 features & 9 features & 15 features \\
\hline Correctly classified instance & $13(54 \%)$ & $13(54 \%)$ & $14(58 \%)$ & $22(92 \%)$ & $24(100 \%)$ & $24(100 \%)$ & 24 & 24 & 24 \\
\hline Incorrectly classified instance & $11(45 \%)$ & $11(45 \%)$ & $10(42 \%)$ & $2(8 \%)$ & $0(0 \%)$ & $0(0 \%)$ & 0 & 0 & 0 \\
\hline Kappa statistics & 0.44 & 0.44 & 0.5 & 0.9 & 1 & 1 & 1 & 1 & 1 \\
\hline Mean absolute error & 0.15 & 0.15 & 0.14 & 0.11 & 0.063 & 0.0394 & 0.0005 & 0.0001 & 0.0001 \\
\hline Root mean square error (\%) & 0.29 & 0.29 & 0.27 & 0.18 & 0.1074 & 0.0694 & 0.0031 & 0.0004 & 0.04 \\
\hline Relative absolute error (\%) & 64 & 64 & 58 & 44 & 26 & 16 & 0.2068 & 0.03 & 0.02 \\
\hline Root relative squared error (\%) & 83 & 83 & 79 & 53 & 31 & 20 & 0.91 & 0.13 & 0.11 \\
\hline
\end{tabular}

TABLE 8: Correlation matrix (PCA).

\begin{tabular}{lcccccccccccccccc}
\hline $\begin{array}{l}\text { Correlation } \\
\text { matrix }\end{array}$ & Area & Mean & StdDev & $X$ & $Y$ & $X M$ & $Y M$ & Major & Minor & Feret & IntDen & Skew & Kurt & fArea & RawIntDen \\
\hline Area & 1 & -0.29 & 0.42 & 1 & 0.98 & 1 & 0.98 & 1 & 1 & 1 & 1 & 0.48 & -0.55 & 1 \\
Mean & -0.29 & 1 & -0.98 & -0.29 & -0.3 & -0.3 & -0.3 & -0.3 & -0.28 & -0.3 & -0.25 & -0.92 & 0.86 & -0.26 & -0.25 \\
StdDev & 0.42 & -0.98 & 1 & 0.42 & 0.44 & 0.43 & 0.44 & 0.44 & 0.41 & 0.43 & 0.38 & 0.98 & -0.94 & 0.4 & 0.38 \\
$X$ & 1 & -0.29 & 0.42 & 1 & 0.99 & 1 & 0.99 & 1 & 0.99 & 1 & 0.99 & 0.48 & -0.56 & 1 & 0.99 \\
$Y$ & 0.98 & -0.3 & 0.44 & 0.99 & 1 & 0.99 & 1 & 0.99 & 0.96 & 0.99 & 0.98 & 0.5 & -0.58 & 0.99 & 0.98 \\
XM & 1 & -0.3 & 0.43 & 1 & 0.99 & 1 & 0.99 & 1 & 0.99 & 1 & 1 & 0.49 & -0.56 & 1 \\
YM & 0.98 & -0.3 & 0.44 & 0.99 & 1 & 0.99 & 1 & 0.99 & 0.96 & 0.99 & 0.98 & 0.5 & -0.58 & 0.99 & 0.98 \\
Major & 1 & -0.3 & 0.44 & 1 & 0.99 & 1 & 0.99 & 1 & 0.98 & 1 & 0.99 & 0.49 & -0.57 & 1 & 0.99 \\
Minor & 1 & -0.28 & 0.41 & 0.99 & 0.96 & 0.99 & 0.96 & 0.98 & 1 & 0.99 & 0.99 & 0.46 & -0.53 & 0.98 & 0.99 \\
Feret & 1 & -0.3 & 0.43 & 1 & 0.99 & 1 & 0.99 & 1 & 0.99 & 1 & 1 & 0.49 & -0.57 & 1 \\
IntDen & 1 & -0.25 & 0.38 & 0.99 & 0.98 & 1 & 0.98 & 0.99 & 0.99 & 1 & 1 & 0.44 & -0.52 & 1 \\
Skew & 0.48 & -0.92 & 0.98 & 0.48 & 0.5 & 0.49 & 0.5 & 0.49 & 0.46 & 0.49 & 0.44 & 1 & -0.99 & 0.46 & 0.44 \\
Kurt & -0.55 & 0.86 & -0.94 & -0.56 & -0.58 & -0.56 & -0.58 & -0.57 & -0.53 & -0.57 & -0.52 & -0.99 & 1 & -0.54 & -0.52 \\
fArea & 1 & -0.26 & 0.4 & 1 & 0.99 & 1 & 0.99 & 1 & 0.98 & 1 & 1 & 0.46 & -0.54 & 1 \\
RawIntDen & 1 & -0.25 & 0.38 & 0.99 & 0.98 & 1 & 0.98 & 0.99 & 0.99 & 1 & 1 & 0.44 & -0.52 & 1 & 1 & 1 \\
\hline
\end{tabular}

TABLE 9: Eigen vectors for each feature.

\begin{tabular}{lccccc}
\hline Eigenvector 1 $(V 1)$ & Eigenvector 2 $(V 2)$ & Features & Eigenvector 1 $(V 1)$ & Eigenvector 2 $(V 2)$ & Features \\
\hline 0.2743 & 0.0889 & Area & 0.2705 & 0.0977 & -0.0589 \\
-0.1184 & 0.5206 & Mean & -0.2704 & 0.0843 & Minor \\
0.1543 & -0.4899 & StdDev & 0.2754 & 0.1163 & Feret \\
0.275 & 0.089 & $X$ & 0.2721 & -0.4647 & IntDen \\
0.2741 & 0.0755 & $Y$ & 0.1695 & 0.4165 & Skew \\
0.2754 & 0.0848 & $X M$ & -0.1879 & 0.1054 & Kurt \\
0.2741 & 0.077 & $Y M$ & 0.2738 & 0.1163 & fArea \\
0.2756 & 0.0817 & Major & 0.2721 & RawIntDen \\
\hline
\end{tabular}

TABLE 10: PCA ranked attributes.

\begin{tabular}{lcc}
\hline Attributes & Characteristic value & Rank \\
\hline 0.276 Major +0.275 Feret $+0.275 X M+0.275 X+0.274$ Area... & 0.1934 & 1 \\
0.521 Mean -0.49 StdDev -0.465 Skew +0.417 Kurt +0.116 IntDen... & 0.0151 & 2 \\
\hline
\end{tabular}




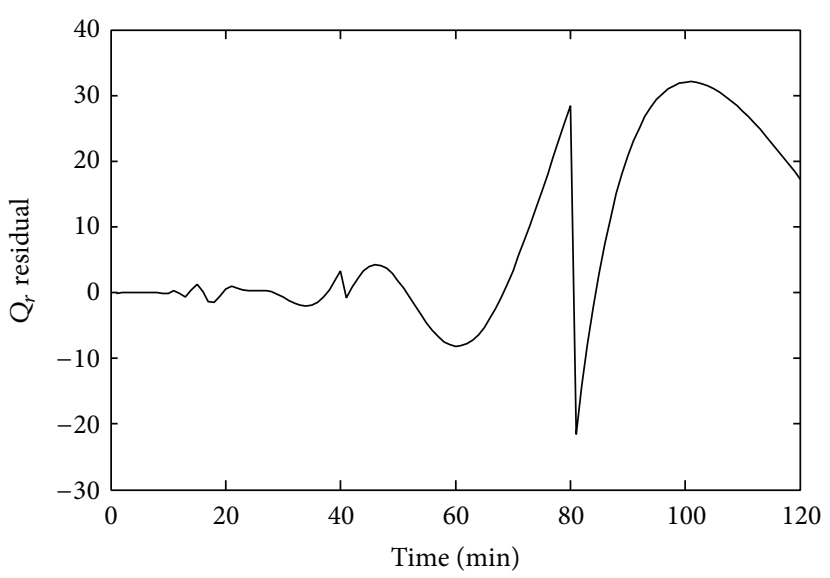

(a)

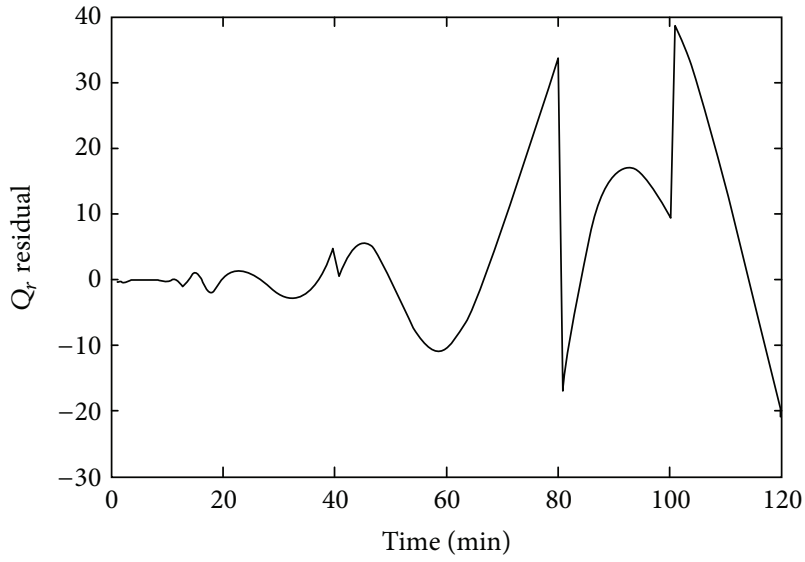

(b)

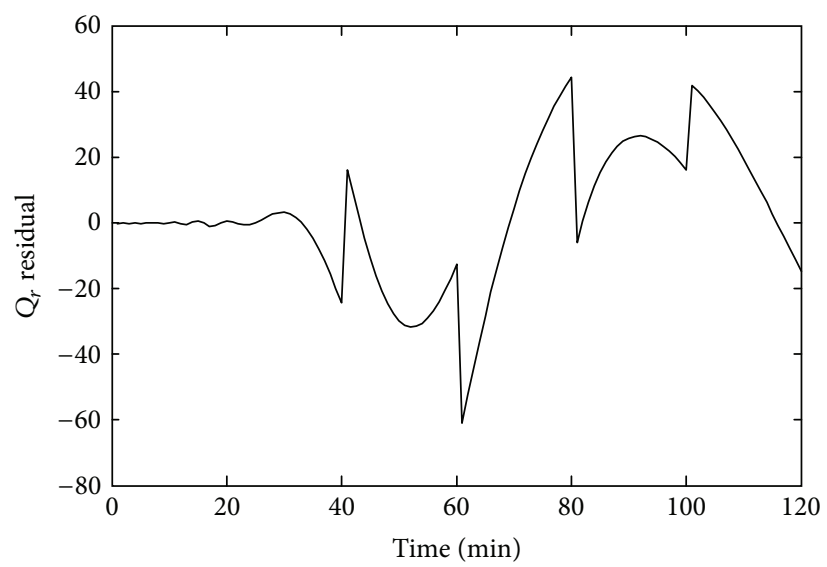

(c)

FIGURE 12: Residual (in terms of $Q_{r}$ ) due to actuator freezing at different time intervals. (a) Residual (in terms of $Q_{r}$ ) due to actuator freezing at the time interval (40-120 min). (b) Residual (in terms of $Q_{r}$ ) due to actuator freezing at the time interval ( $80-100$ min). (c) Residual (in terms of $Q_{r}$ ) due to actuator freezing at the time interval (40-60 min).

TABLE 11: Classifier performance comparison based on PCA and SVM.

\begin{tabular}{|c|c|c|c|c|c|c|}
\hline \multirow{2}{*}{ Classifiers } & \multicolumn{2}{|c|}{ Bayes net } & \multicolumn{2}{|c|}{ MLP } & \multicolumn{2}{|c|}{$\mathrm{RBF}$} \\
\hline & SVM & PCA & SVM & PCA & SVM & PCA \\
\hline Correctly classified instance & $13(54 \%)$ & $12(50 \%)$ & $24(100 \%)$ & $19(79 \%)$ & $24(100 \%)$ & $24(100 \%)$ \\
\hline Incorrectly classified instance & $11(45 \%)$ & $12(50 \%)$ & $0(0 \%)$ & $5(20 \%)$ & 0 & 0 \\
\hline Kappa statistics & 0.44 & 0.39 & 1 & 0.746 & 1 & 1 \\
\hline Mean absolute error & 0.15 & 0.19 & 0.063 & 0.15 & 0.0001 & 0.0001 \\
\hline Root mean square error (\%) & 0.29 & 0.3 & 0.1074 & 0.245 & 0.04 & 0.006 \\
\hline Relative absolute error (\%) & 64 & 81 & 26 & 62 & 0.02 & 0.03 \\
\hline Root relative squared error (\%) & 83 & 86 & 31 & 71 & 0.11 & 0.31 \\
\hline
\end{tabular}

square error are less for RBF than MLP. So RBF classifier performance is better than MLP for this fault classification study.

From the SVM ranked classifier's performance, it has been realised that the RBF is performing well even for less number of features and the MLP and Bayes performances are poor for less data. From the results, it could be observed that 9 features are enough to make all the classifiers' performance good. The SVM attribute filter is used to reduce the number of input data.

The features are reduced by using PCA technique also. The correlation is the measure of similarity and the value 


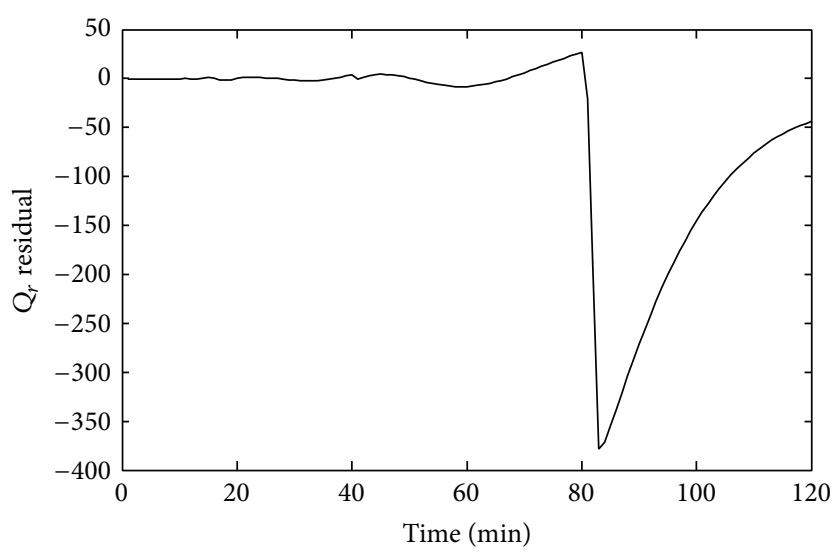

(a)

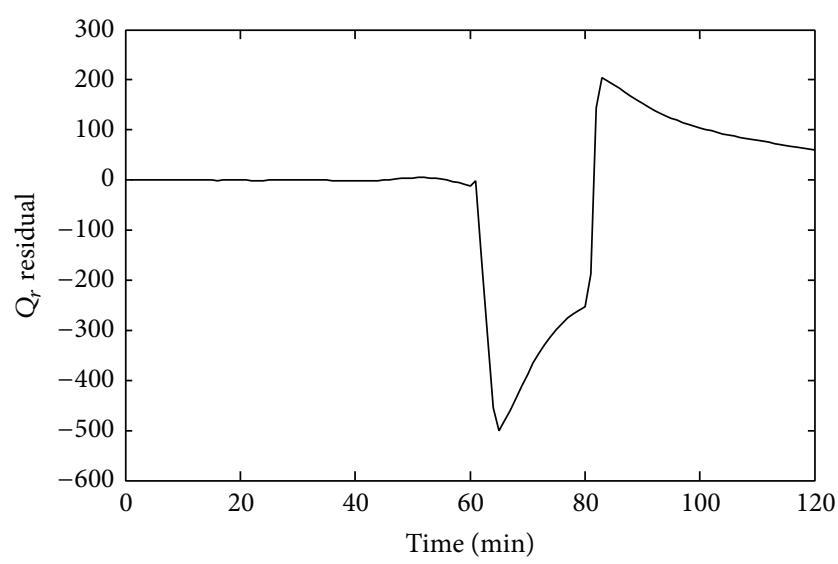

(c)

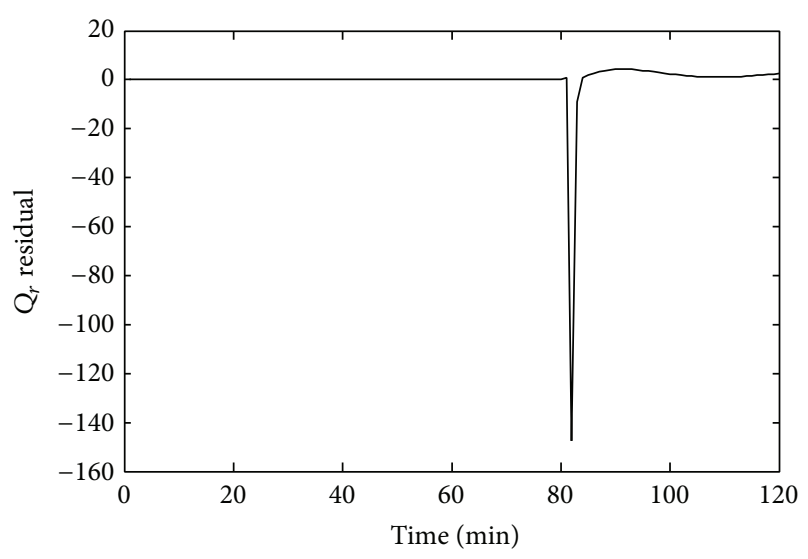

(b)

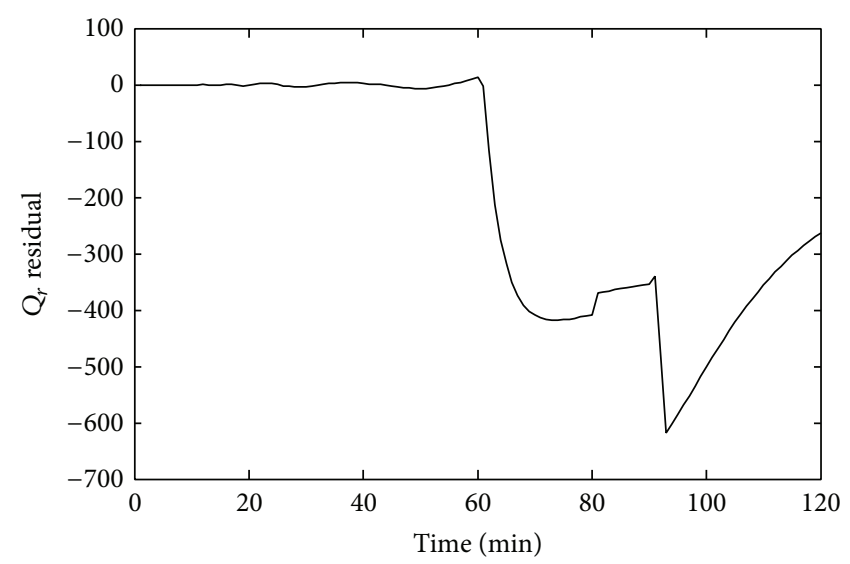

(d)

FIGURE 13: Residual (in terms of $Q_{r}$ ) due to actuator biasing at different intervals. (a) Residual (in terms of $Q_{r}$ ) due to actuator biasing at the time interval ( $80 \mathrm{~min}$ ). (b) Residual (in terms of $Q_{r}$ ) due to actuator biasing at the time interval ( $80 \mathrm{~min}$ ). (c) Residual (in terms of $Q_{r}$ ) due to actuator biasing at the time interval $(60 \mathrm{~min})$. (d) Residual (in terms of $Q_{r}$ ) due to actuator biasing at the time interval ( $90 \mathrm{~min}$ ).

for correlation is 1 and then the patterns are similar. If the correlation is " 0 " or negative then the patterns are dissimilar. The diagonal values of the correlation matrix shown in Table 8 are " 1 " which indicates that the similarity measure is calculated for the image with itself (autocorrelation). The other entries denote the cross correlation that is computed.

The eigenvectors of a square matrix are the nonzero vectors after being multiplied by the matrix, remaining proportional to the original vector (i.e., change only in magnitude, not in direction). The eigenvectors corresponding to the features are displayed in Table 9. For each eigenvector, the corresponding eigenvalue is the factor by which the eigenvector changes when multiplied by the matrix as they represent the characteristic values shown in Table 10.

Table 11 shows the classifier performance based on the SVM with 9 features and PCA with full data as two attributes are more or less same for the RBF classifier. But for MLP and also for Bayes net, the SVM attribute filter based classification results show its better nature than PCA.

\section{Conclusion}

This paper proposes a method for classification of various faults of the batch reactor by using artificial neural network (ANN) classifiers such as multilayer perceptron (MLP), radial basis function (RBF), and Bayes net from fault signatures. It is based on the relationship of each fault's impact on heat release $\left(Q_{r}\right)$ of the reactor, which is the immeasurable parameter, estimated by SVM estimator. The fault signature trend is varying from fault to fault. Most appropriate features are selected from the variety of fault signatures and the numbers of attributes are reduced based on the SVM attribute filter by using ranking method and PCA, to reduce the computational difficulty of classifiers. It is observed that the classification accuracy of RBF and MLP is better than the Bayes net from the classifiers performance during training. Based on the performance criteria, the RBF performs well compared to MLP and Bayes net within 24 instances under the assumption that in practical situation less historical data are available. The results verify that the capability of the proposed fault diagnosis scheme is efficient and fast by using general ANN 


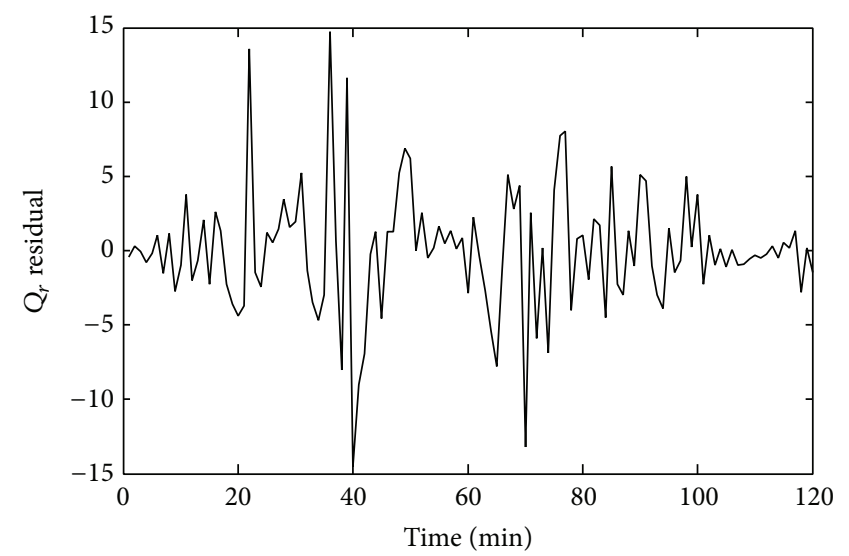

(a)

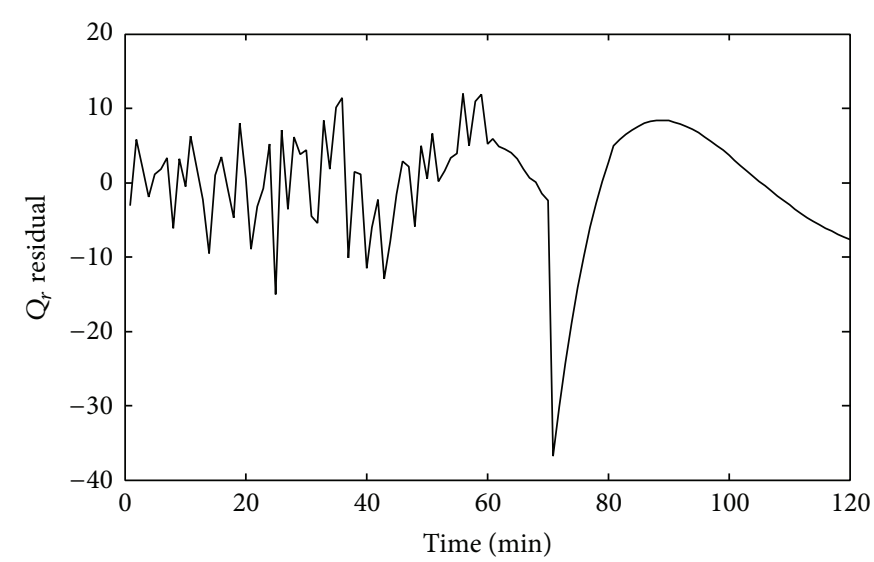

(b)

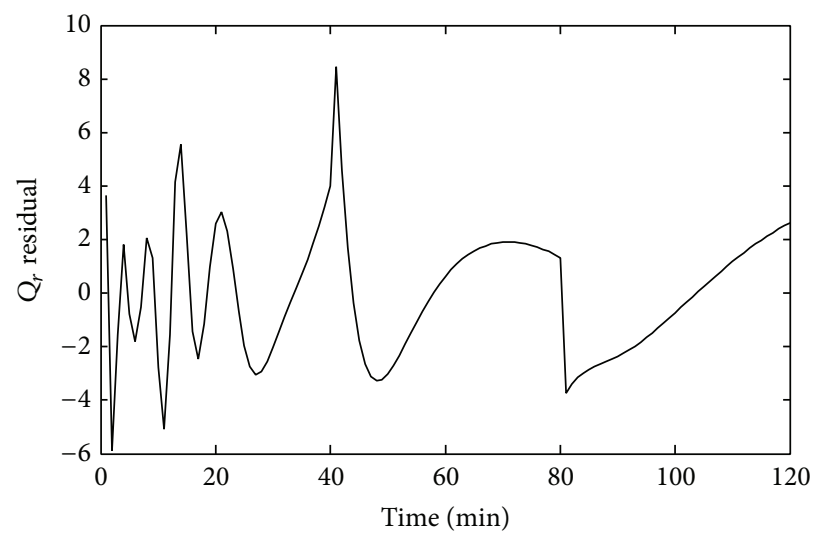

(c)

Figure 14: Residual (in terms of $Q_{r}$ ) due to sensor fault. (a) Residual (in terms of $Q_{r}$ ) due to reactor temperature sensor measurement with white noise. (b) Residual (in terms of $Q_{r}$ ) due to abrupt zero in reactor temperature sensor measurement. (c) Residual (in terms of $Q_{r}$ ) due to bias in jacket temperature sensor measurement.

classifiers. It is based on the limited number of features extracted and selected from only one estimated parameter $\left(Q_{r}\right)$ itself. In future, it can be applied to develop a knowledge based system which is useful for early diagnosis of fault, to minimize the risk of thermal runaway for safety purpose of the batch reactor as well as to reduce the operating cost.

\section{Conflict of Interests}

The authors declare that there is no conflict of interests regarding the publication of this paper.

\section{References}

[1] A. M. Benkouider, J. C. Buvat, J. M. Cosmao, and A. Saboni, "Fault detection in semi-batch reactor using the EKF and statistical method," Journal of Loss Prevention in the Process Industries, vol. 22, no. 2, pp. 153-161, 2009.

[2] D. Ruiz, J. M. Nougués, Z. Calderón, A. Espuña, and L. Puigjaner, "Neural network based framework for fault diagnosis in batch chemical plants," Computers and Chemical Engineering, vol. 24 , no. $2-7$, pp. 777-784, 2000.
[3] V. Venkatasubramanian and K. Chan, "Neural network methodology for process fault diagnosis," AIChE Journal, vol. 35, no. 12, pp. 1993-2002, 1989.

[4] S. Saludes and M. J. Fuente, "Support vector based novelty detection for fault tolerant control," in Proceedings of the 44th IEEE Conference on Decision and Control, and the European Control Conference (CDC-ECC '05), pp. 5820-5825, Seville, Spain, December 2005.

[5] I. Monroy, R. Benitez, G. Escudero, and M. Graells, "A semisupervised approach to fault diagnosis for chemical processes," Computers and Chemical Engineering, vol. 34, no. 5, pp. 631-642, 2010.

[6] P. K. Kankar, S. C. Sharma, and S. P. Harsha, "Fault diagnosis of ball bearings using machine learning methods," Expert Systems with Applications, vol. 38, no. 3, pp. 1876-1886, 2011.

[7] H. J. Shin, D.-H. Eom, and S.-S. Kim, "One-class support vector machines - an application in machine fault detection and classification," Computers and Industrial Engineering, vol. 48, no. 2, pp. 395-408, 2005.

[8] T.-S. Li, "Applying wavelets transform and support vector machine for copper clad laminate defects classification," Computers and Industrial Engineering, vol. 56, no. 3, pp. 1154-1168, 2009. 
[9] K. Salahshoor, M. Kordestani, and M. S. Khoshro, "Fault detection and diagnosis of an industrial steam turbine using fusion of SVM (support vector machine) and ANFIS (adaptive neuro-fuzzy inference system) classifiers," Energy, vol. 35, no. 12, pp. 5472-5482, 2010.

[10] Q. Yang, J. Guo, and X. Zhang, "FastICA-SVM fault diagnosis for batch process," in Proceedings of the 7th International Conference on Natural Computation (ICNC '11), pp. 1649-1653, July 2011.

[11] J. A. K. Suykens and J. Vandewalle, "Least squares support vector machine classifiers," Neural Processing Letters, vol. 9, no. 3, pp. 293-300, 1999.

[12] J. S. R. Jang, C. T. Sun, and E. Mizutani, Neuro-Fuzzy and Soft Computing Computational Approach to Learning and Machine Intelligence, Prentice Hall of India, 2002.

[13] R. E. Neapolitan, Probabilistic Reasoning in Expert Systems: Theory and Algorithms, John Wiley \& Sons, 1989.

[14] J. Pearl, Probabilistic Reasoning in Intelligent Systems, Morgan Kaufmann, San Francisco, Calif, USA, 1988.

[15] H. Simon, Neural Networks-A Comprehensive Foundation, Pearson Education, San Francisco, Calif, USA, 2005.

[16] M. J. Zurada, Introduction to Artificial Neural Systems, Delhi Jaico Publishing House, 1999.

[17] B. J. Cott and S. Macchietto, "Temperature control of exothermic batch reactors using generic model control," Industrial and Engineering Chemistry Research, vol. 28, no. 8, pp. 1177-1184, 1989.

[18] N. Aziz, M. A. Hussain, and I. M. Mujtaba, "Performance of different types of controllers in tracking optimal temperature profiles in batch reactors," Computers and Chemical Engineering, vol. 24, no. 2-7, pp. 1069-1075, 2000.

[19] I. M. Mujtaba, N. Aziz, and M. A. Hussain, "Neural network based modelling and control in batch reactor," Chemical Engineering Research and Design, vol. 84, no. 8, pp. 635-644, 2006.

[20] S. Sujatha and N. Pappa, "Realization of non linear controllers in batch reactor using GA and SVM," International Journal of Chemical Reactor Engineering, vol. 9, no. 1, 2011.

[21] P. L. Lee and G. R. Sullivan, "Generic model control (GMC)," Computers and Chemical Engineering, vol. 12, no. 6, pp. 573-580, 1988.

[22] S. W. Choi, J. Morris, and I.-B. Lee, "Nonlinear multiscale modelling for fault detection and identification," Chemical Engineering Science, vol. 63, no. 8, pp. 2252-2266, 2008. 

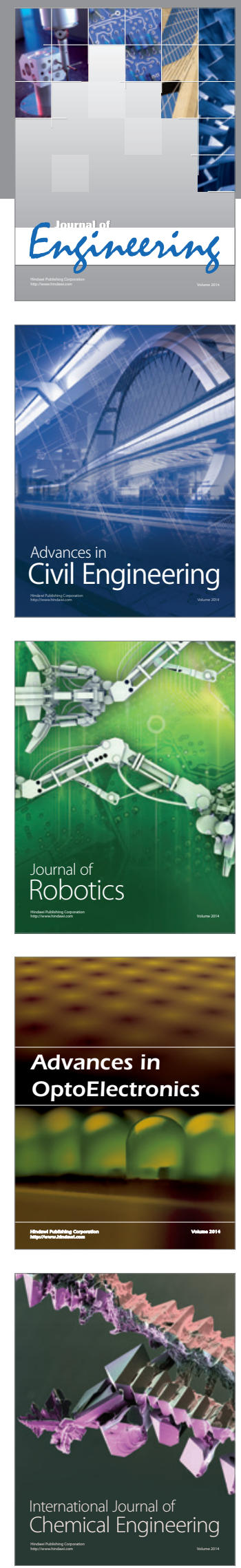

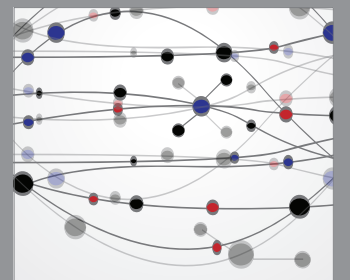

The Scientific World Journal
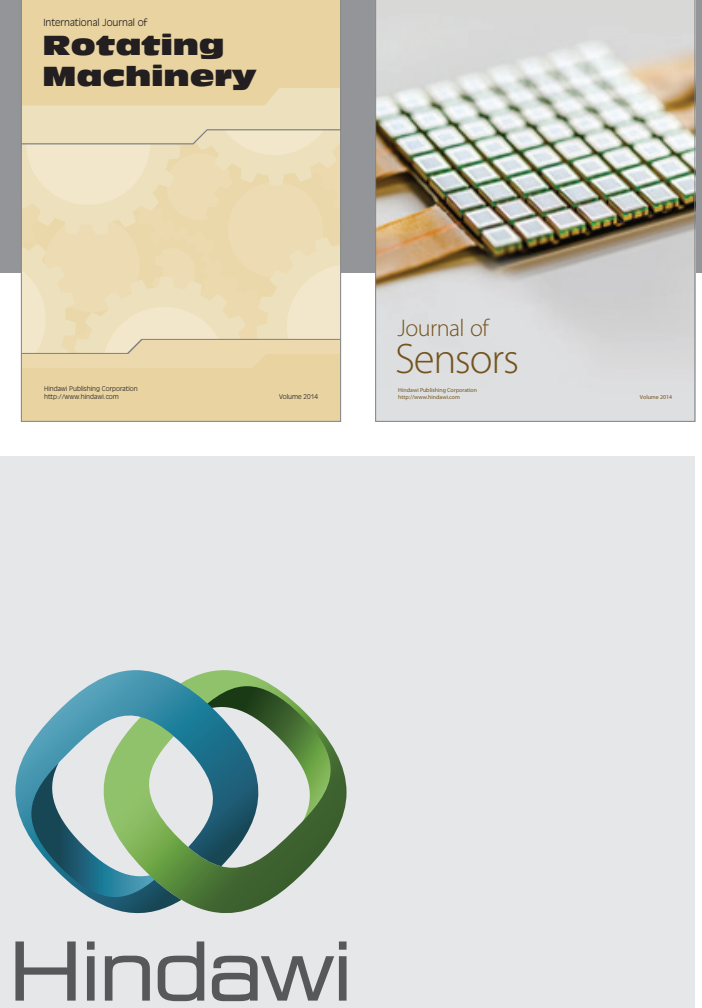

Submit your manuscripts at http://www.hindawi.com
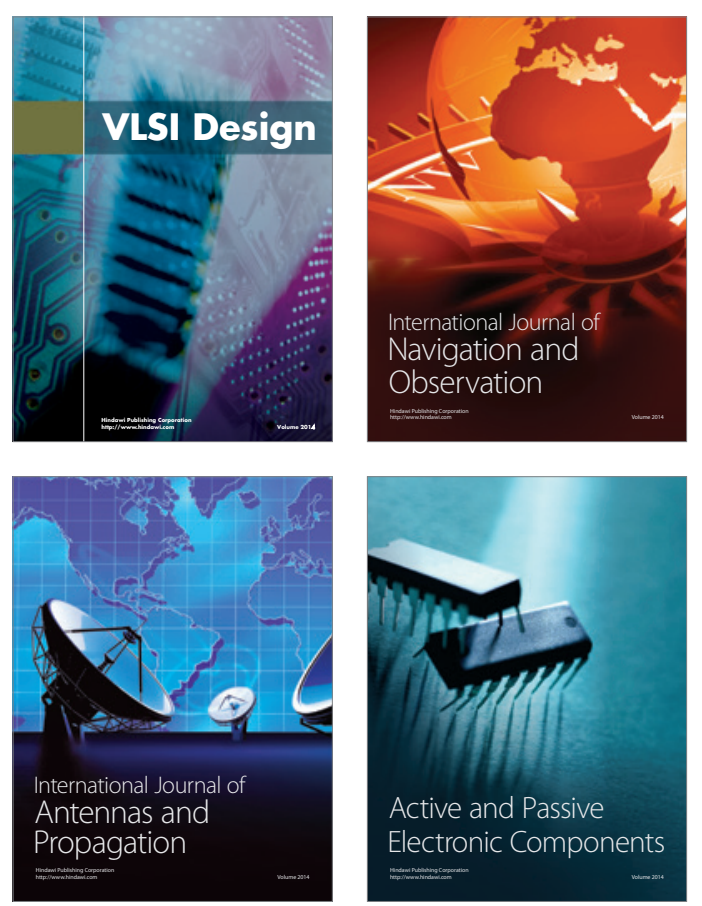
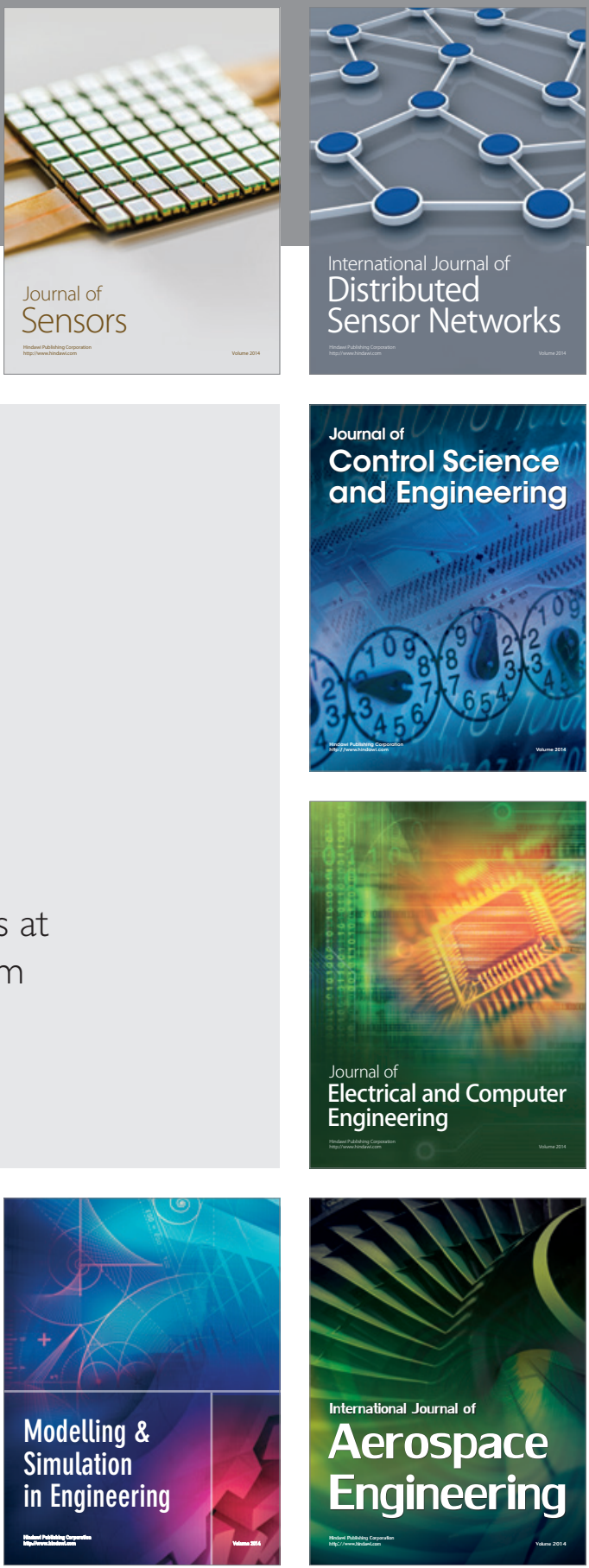

Journal of

Control Science

and Engineering
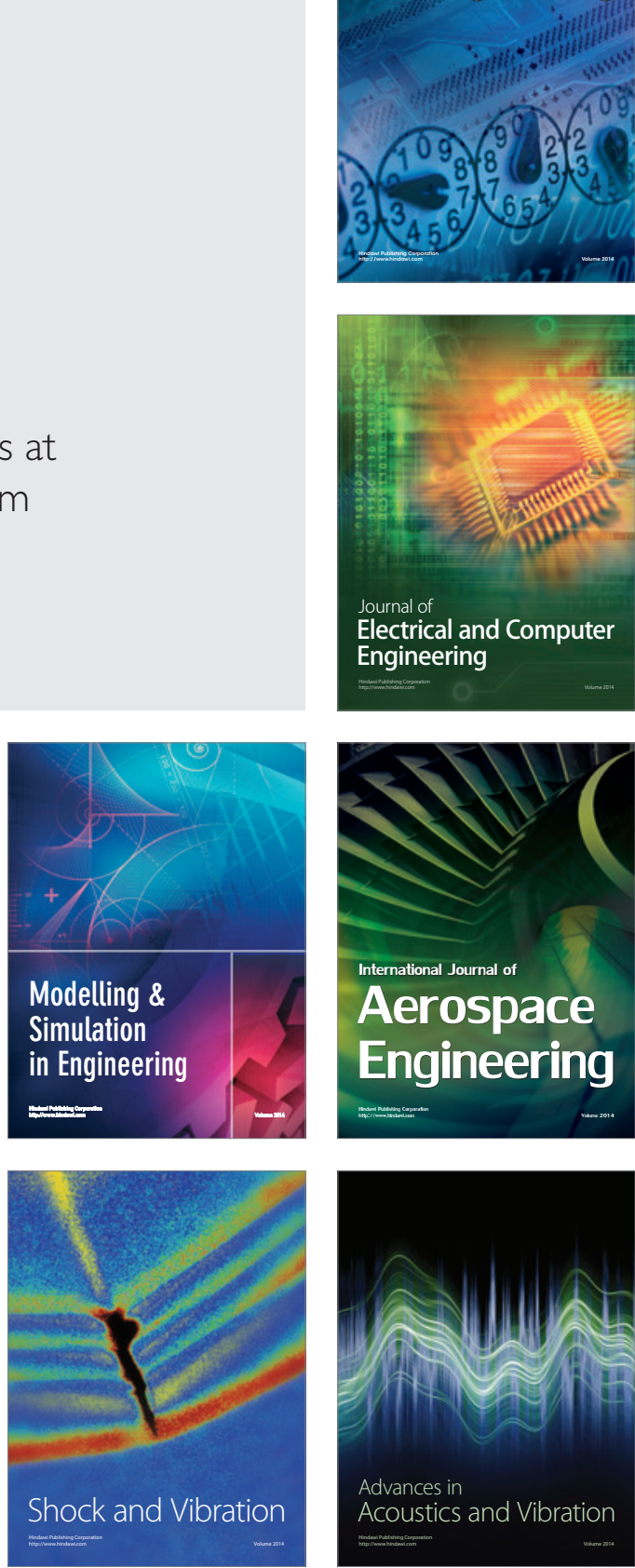